\title{
The Influencing Factors of Postoperative Delirium in Elderly Hip Fracture Patients: What Should Treatment Focus On
}

\section{Chunwen Yan}

hainan hospital of Chinese medicine

Min Yang

Hainan hospital of Chinese medicine

Nasha Niu

hainan hospital of Chinese medicine

Linmei Li

hainan hospial of Chinese medicine

Li Pan ( $\nabla$ yrmya172512@163.com )

Hainan hospital of Chinese medicine

Research article

Keywords: delirium, surgery, hip fracture, treatment, care, prevention

Posted Date: November 2nd, 2021

DOI: https://doi.org/10.21203/rs.3.rs-944711/v1

License: (9) This work is licensed under a Creative Commons Attribution 4.0 International License.

Read Full License 


\section{Abstract}

Background: The postoperative delirium is a common yet serious complication in elderly patients with hip fracture, it's necessary to evaluate the potential risk factors of delirium in patients with hip fracture, to provide reliable evidence to the clinical management of hip fracture.

Methods: Elderly patients who underwent hip fracture surgery in our hospital from June 1, 2019 to May 31,2021 were selected. The characteristics and treatment data of delirium and no delirium patients were collected and compared. Multivariate logistic regression analysis was conducted to analyze the influencing factors affecting postoperative delirium in elderly patients with hip fracture.

Results: A total of 245 patients with hip fracture were included, the incidence of postoperative delirium in patients with hip fracture was $13.06 \%$. There were significant differences in the age, BMI, history of delirium, estimated blood loss and duration of surgery (all $p<0.05$ ). There were significant differences in the albumin and TSH between delirium and no delirium group(all $p<0.05)$, Logistics analyses indicated that ge $\geq 75 \mathrm{y}(\mathrm{OR} 3.112,95 \% \mathrm{Cl} 1.527 \sim 5.742), \mathrm{BMI} \geq 24 \mathrm{~kg} / \mathrm{m}^{2}(\mathrm{OR} 2.127,95 \% \mathrm{Cl} 1.144 \sim 3.598)$, history of delirium(OR1.754,95\%Cl1.173 2.347), estimated blood loss $\geq 400 \mathrm{ml}(\mathrm{OR} 1.698,95 \% \mathrm{Cl} 1.427 \sim 1.946)$, duration of surgery $\geq 120 \mathrm{~min}(\mathrm{OR} 2.138,95 \% \mathrm{Cl} 1.126 \sim 3.085)$, preoperative albumin $\leq 40 \mathrm{~g} / \mathrm{L}(\mathrm{OR} 1.845,95 \% \mathrm{Cl} 1.102 \sim 2.835)$ and $\mathrm{TSH} \leq 2 \mathrm{mU} / \mathrm{L}(\mathrm{OR} 2.226,95 \% \mathrm{Cl} 1.329 \sim 4.011)$ were the independent risk factors of postoperative delirium in patients with hip fracture(all $p<0.05)$.

Conclusions: Postoperative delirium is very common in elderly patients with hip fracture, and it was associated with many risk factors, clinical preventions targeted on those risk factors are needed to reduce the postoperative delirium.

\section{Background}

With the aging of the population, the incidence of hip fractures is increasing year by year[1]. It is reported that the incidence of hip fractures is $11.1 \%$ in men and $22.7 \%$ in women[2, 3]. Almost half of hip fractures occur in patients 70 years of age or older, and it is estimated that $18-28 \%$ of elderly hip fracture patients die within a year[4]. Hip fractures in the elderly seriously affect their quality of life and bring about a lasting decline in physical fitness, which leads to an increase in the morbidity and mortality[5]. Postoperative delirium is the most common type of complication after hip fracture[6, 7]. Delirium is an acute mental disorder, which is often manifested as a decrease in concentration, sustained ability, and easy to be interfered with[8]. During the illness, there are fluctuations in the condition every day, usually manifested as daytime sleepiness and night irritability. Studies $[9,10]$ have reported that patients with delirium hip fractures during hospitalization have a worse prognosis than those without delirium. Delirium during the perioperative period will seriously affect the patient's treatment effect, increase the mortality rate or the need for home care after discharge, increase the number of hospitalization days, costs, and hospital-acquired complications[11, 12] . 
In clinical practice, it is often due to the lack of knowledge of medical staff and the complexity and change of symptoms, which is about $32.46 \%$ of delirium is often undetected or not treated, which will bring more serious consequences to the patient[13]. 30-40\% of perioperative delirium can be prevented, and effective prevention of delirium can minimize its occurrence and related adverse consequences[14, 15]. Therefore, we aimed to analyze the characteristics and related influencing factors of postoperative delirium in patients with hip fractures, to provide evidence support for the treatment of clinical hip fractures and the prevention of postoperative delirium.

\section{Methods}

\section{Ethics}

In this study, all methods were performed in accordance with the relevant guidelines and regulations. Our study had been verified and approved by the ethical committee of Hainan Hospital of Chinese Medicine affiliated to Guangzhou University of Chinese Medicine (approval number:190084). For patients with delirium, the written informed consent from guardians for such patients were obtained. And for the patients without delirium, written informed consents were obtained from patients.

\section{Patients}

Elderly patients who underwent hip fracture surgery in our hospital from June 1, 2019 to May 31, 2021 were selected as the research patients. The inclusion criteria for patients in this study were: age $\geq$ 60 years; the hip fracture met the diagnostic criteria for hip fractures; patient underwent elective surgery in our hospital; all patients and their families had been informed and signed an informed consent form; clinical data was complete. Exclusion criteria: patients with a history of brain surgery; patients with hearing impairment; patients with malignant tumors; patients taking sedatives or antidepressants; patients who were unwilling to participate in this study.

Diagnosis of delirium

According to the diagnostic criteria in the fifth edition of the Diagnostic and Statistical Manual of Mental Disorders (DSM-V) of the American Psychiatric Association[16], the confusion assessment method (CAM) was used as a diagnostic tool for the diagnosis of delirium[17]. CAM includes 4 items: 『acute onset and fluctuating changes in mental state; खinattention; \thinking disorder; 『change of consciousness level.

\section{Data collection}

Two authors independently collected following clinical data: age, gender, body mass index(BMI), hypertension, diabetes mellitus, hyperlipidemia, history of delirium, type of fracture, postoperative ability of daily living(ADL) score, method of anesthesia, estimated blood loss and duration of surgery. Besides, all patients underwent preoperative laboratory examinations. We collected following indicators: albumin, hemoglobin, blood sugar, creatinine, urea nitrogen, triiodothyronine(T3), thyroxine (T4), serum thyroid stimulating hormone (TSH), 
Free triiodothyronine (FT3), free thyroxine (FT4), arterial partial pressure of oxygen $\left(\mathrm{PaO}_{2}\right)$

arterial partial pressure of carbon dioxide $\left(\mathrm{PaCO}_{2}\right)$.

Statistical method

We used SPSS 25. 0 Software to carries out statistical analysis of relevant data. Measurement data was expressed by mean \pm standard deviation, measurement data between groups was expressed by independent sample t test, count data was expressed by number of cases and percentage, and count data were compared by Chi-square test. We used multivariate logistic regression to analyze the factors affecting postoperative delirium in elderly patients with hip fracture. In this study, $\mathrm{P}<0.05$ meant that the difference between the groups was statistically significant.

\section{Results}

The characteristics of included patients

A total of 245 patients with hip fracture were included in this study, and 32 patients had been diagnosed as delirium, the incidence of postoperative delirium in patients with hip fracture was $13.06 \%$. As showed in Table 1, there were significant differences in the age, BMI, history of delirium, estimated blood loss and duration of surgery(all $p<0.05$ ). No significant differences in the gender, hypertension, diabetes mellitus, hyperlipidemia, type of fracture, postoperative ADL score and method of anesthesia had been found (all $p>0.05$ ). 
Table 1

The characteristics of included patients

\begin{tabular}{|c|c|c|c|c|}
\hline Items & Delirium group(n=32) & No delirium group $(n=213)$ & $t / \chi^{2}$ & $\mathbf{p}$ \\
\hline $\operatorname{Age}(y)$ & $78.84 \pm 7.36$ & $71.21 \pm 5.83$ & 10.731 & 0.014 \\
\hline Male/female & $12 / 20$ & $84 / 129$ & 1.926 & 0.085 \\
\hline $\mathrm{BMI}\left(\mathrm{kg} / \mathrm{m}^{2}\right)$ & $25.32 \pm 3.56$ & $21.20 \pm 2.98$ & 1.142 & 0.026 \\
\hline Hypertension & $21(62.63 \%)$ & $110(51.64 \%)$ & 1.165 & 0.101 \\
\hline Diabetes mellitus & $13(40.63 \%)$ & $78(36.62 \%)$ & 1.224 & 0.094 \\
\hline Hyperlipidemia & $14(43.75 \%)$ & $82(38.50 \%)$ & 1.707 & 0.089 \\
\hline History of delirium & $17(53.13 \%)$ & $19(8.92 \%)$ & 1.113 & 0.021 \\
\hline Type of fracture & & & 1.188 & 0.107 \\
\hline Femoral neck fracture & $13(40.63 \%)$ & $81(38.03 \%)$ & & \\
\hline Intertrochanteric fracture & $18(56.25 \%)$ & $129(60.56 \%)$ & & \\
\hline Subtrochanteric fracture & $1(3.12 \%)$ & $3(1.41 \%)$ & & \\
\hline Preoperative ADL score & $95.42 \pm 7.18$ & $94.95 \pm 9.84$ & 22.107 & 0.073 \\
\hline Method of anesthesia & & & 1.882 & 0.096 \\
\hline Lumbar anaesthesia & $19(59.38 \%)$ & $124(58.22 \%)$ & & \\
\hline General anaesthesia & $13(40.63 \%)$ & $89(41.78 \%)$ & & \\
\hline Estimated blood loss(ml) & $455.07 \pm 62.85$ & $369.12 \pm 58.23$ & 38.467 & 0.002 \\
\hline Duration of surgery(min) & $147.12 \pm 36.77$ & $102.37 \pm 24.16$ & 19.236 & 0.008 \\
\hline
\end{tabular}

Preoperative laboratory examination results

As showed in Table 2, there were significant differences in the albumin and TSH between delirium and no delirium group(all $p<0.05$ ), no significant differences in the hemoglobin, blood sugar, creatinine, urea nitrogen, $\mathrm{T} 3, \mathrm{~T} 4, \mathrm{FT} 3, \mathrm{FT} 4, \mathrm{PaO}_{2}$ and $\mathrm{PaCO}_{2}$ were found(all $\mathrm{p}>0.05$ ). 
Table 2

The preoperative laboratory examination results

\begin{tabular}{|lllll|}
\hline Items & Delirium group $(\mathrm{n}=32)$ & No delirium group $(\mathbf{n}=213)$ & $\mathrm{t} / \mathbf{\chi}^{2}$ & $\mathbf{p}$ \\
\hline Albumin(g/L) & $38.05 \pm 6.22$ & $44.96 \pm 5.34$ & 7.116 & 0.025 \\
\hline Hemoglobin(g/L) & $122.03 \pm 19.74$ & $120.84 \pm 14.09$ & 17.253 & 0.091 \\
\hline Blood sugar(mmol/L) & $7.42 \pm 1.08$ & $7.51 \pm 1.33$ & 1.650 & 0.102 \\
\hline Creatinine( $\mu \mathrm{mol} / \mathrm{L})$ & $76.95 \pm 8.31$ & $75.32 \pm 8.84$ & 6.041 & 0.087 \\
\hline Urea nitrogen(mmol/L) & $7.73 \pm 1.02$ & $7.24 \pm 1.27$ & 1.636 & 0.099 \\
\hline $\mathrm{T} 3(\mathrm{mU} / \mathrm{L})$ & $1.41 \pm 0.12$ & $1.38 \pm 0.11$ & 1.204 & 0.112 \\
\hline $\mathrm{T} 4(\mathrm{mU} / \mathrm{L})$ & $95.03 \pm 12.54$ & $96.23 \pm 14.04$ & 8.345 & 0.063 \\
\hline $\mathrm{TSH}(\mathrm{mU} / \mathrm{L})$ & $1.62 \pm 0.22$ & $2.74 \pm 0.52$ & 1.224 & 0.022 \\
\hline $\mathrm{FT3}(\mathrm{mU} / \mathrm{L})$ & $3.13 \pm 0.97$ & $3.30 \pm 0.83$ & 1.137 & 0.059 \\
\hline $\mathrm{FT4}(\mathrm{mU} / \mathrm{L})$ & $16.84 \pm 4.03$ & $16.59 \pm 5.18$ & 3.284 & 0.064 \\
\hline $\mathrm{PaO}_{2}(\mathrm{mmHg})$ & $84.36 \pm 12.65$ & $86.89 \pm 15.11$ & 9.705 & 0.131 \\
\hline $\mathrm{PaCO}_{2}(\mathrm{mmHg})$ & $33.82 \pm 5.78$ & $32.41 \pm 6.05$ & 4.822 & 0.061 \\
\hline
\end{tabular}

Logistic regression analyses

The variable assignment of multivariate logistic regression were presented in Table 3. As indicated in Table 4, Age $\geq 75 y$ (OR3.112,95\%Cl1.527 5.742), BMI $\geq 24 \mathrm{~kg} / \mathrm{m}^{2}$ (OR2.127,95\%Cl1.144 3.598), history of delirium(OR1.754,95\%Cl1.173 2.347), estimated blood loss $\geq 400 \mathrm{ml}(\mathrm{OR} 1.698,95 \% \mathrm{Cl} 1.427$ 1.946), duration of surgery $\geq 120 \mathrm{~min}(\mathrm{OR} 2.138,95 \% \mathrm{Cl} 1.126 \sim 3.085)$, preoperative albumin $\leq 40 \mathrm{~g} / \mathrm{L}(\mathrm{OR} 1.845,95 \% \mathrm{Cl} 1.102 \sim 2.835)$ and $\mathrm{TSH} \leq 2 \mathrm{mU} / \mathrm{L}(\mathrm{OR} 2.226,95 \% \mathrm{Cl} 1.329 \sim 4.011)$ were the independent risk factors of postoperative delirium in patients with hip fracture(all $p<0.05)$. 
Table 3

The variable assignment of multivariate logistic regression

\begin{tabular}{|lll|}
\hline Factors & Variables & Assignment \\
\hline Delirium & $Y$ & Yes=1, no=2 \\
\hline Age $(\mathrm{y})$ & $\mathrm{X}_{1}$ & $\geq 75 \mathrm{y}=1,<75 \mathrm{y}=2$ \\
\hline BMI $\left(\mathrm{kg} / \mathrm{m}^{2}\right)$ & $\mathrm{X}_{2}$ & $\geq 24=1,<24=2$ \\
\hline History of delirium & $\mathrm{X}_{3}$ & Yes=1, no=2 \\
\hline Estimated blood loss $(\mathrm{ml})$ & $\mathrm{X}_{4}$ & $\geq 400=1,<400=2$ \\
\hline Duration of surgery $(\mathrm{min})$ & $\mathrm{X}_{5}$ & $\geq 120=1,<120=2$ \\
\hline Albumin(g/L) & $\mathrm{X}_{6}$ & $\leq 40=1,>40=2$ \\
\hline TSH(mU/L) & $X_{7}$ & $\leq 2=1,>2=2$ \\
\hline
\end{tabular}

Table 4

Logistic regression analysis on the risk factors of postoperative delirium in patients with hip fracture

\begin{tabular}{|llllll|}
\hline Items & $\boldsymbol{\beta}$ & $\mathrm{SE}$ & $\mathrm{OR}$ & $95 \% \mathrm{Cl}$ & $\mathbf{p}$ \\
\hline Age $\geq 75 \mathrm{y}$ & 0.122 & 0.495 & 3.112 & $1.527 \sim 5.742$ & 0.012 \\
\hline $\mathrm{BMI} \geq 24 \mathrm{~kg} / \mathrm{m}^{2}$ & 0.217 & 0.356 & 2.127 & $1.144 \sim 3.598$ & 0.029 \\
\hline History of delirium & 0.143 & 0.518 & 1.754 & $1.173 \sim 2.347$ & 0.042 \\
\hline Estimated blood loss $\geq 400 \mathrm{ml}$ & 0.257 & 0.522 & 1.698 & $1.427 \sim 1.946$ & 0.013 \\
\hline Duration of surgery $\geq 120 \mathrm{~min}$ & 0.187 & 0.236 & 2.138 & $1.126 \sim 3.085$ & 0.046 \\
\hline Albumin $\leq 40 \mathrm{~g} / \mathrm{L}$ & 0.124 & 0.331 & 1.845 & $1.102 \sim 2.835$ & 0.017 \\
\hline TSH $\leq 2 \mathrm{mU} / \mathrm{L}$ & 0.114 & 0.642 & 2.226 & $1.329 \sim 4.011$ & 0.009 \\
\hline
\end{tabular}

\section{Discussions}

Postoperative delirium refers to the acute psychopathic syndrome with cognitive dysfunction and other related symptoms as the main manifestation after the patient undergoes surgery. The delirium patient has disturbances in consciousness, perception, thinking, mood, memory, attention, and sleep cycle[18]. Postoperative delirium has a high morbidity and related mortality in elderly patients[19]. According to reports[20,21], the incidence of delirium after hip fracture in the elderly ranges from $5.15-48.37 \%$, which may be related to the differences of diagnostic criteria of delirium. Previous study[22] has analyzed 232 cases of elderly patients with hip fracture and has found that delirium occurred in $30.2 \%$ of patients, and 
the survival rate of this part of patients 40 months after surgery was $63.6 \%$, which was much lower than the normal patient's survival rate of $81.0 \%$. Besides, previous studies[23-25] have founded that patients with delirium have longer hospital stays, higher medical costs, and the incidence of dementia after discharge can be as high as $38 \%$, and postoperative hip function and independent living ability of delirium patients are difficult to restore to the preoperative level, which seriously affects the prognosis of patients. Therefore, early prevention, detection and treatment of delirium have important clinical significance for improving the prognosis of patients with hip fracture. The results of our study have indicated that the incidence of postoperative delirium in patients with hip fracture is $13.06 \%$, and age $\geq 75 \mathrm{y}, \mathrm{BMl} \geq 24 \mathrm{~kg} / \mathrm{m}^{2}$, history of delirium, estimated blood loss $\geq 400 \mathrm{ml}$, duration of surgery $\geq 120 \mathrm{~min}$, preoperative albumin $\leq 40 \mathrm{~g} / \mathrm{L}$ and $\mathrm{TSH} \leq 2 \mathrm{mU} / \mathrm{L}$ were the independent risk factors of postoperative delirium in patients with hip fracture, clinical measures targeted on those risk factors are needed to prevent the onset and development of postoperative delirium.

With the increase of age, the organs and tissues of elderly patients degenerate and their functions decline, and there are often many chronic underlying medical diseases such as the cardiovascular system, respiratory system, and endocrine system[26]. At the same time, they are also easy to merge due to decreased appetite and intake, and metabolic disorders, leading to malnutrition[27]. Studies[28, 29] have shown that elderly patients with hip fractures $\geq 73$ years of age are 1.83 times more likely to develop delirium after surgery than those aged $<73$ years. At the same time, studies[30, 31] have shown that age is attributable to preoperative malnutrition in elderly patients with medullary fractures, and it is one of the main risk factors of delirium in elderly patients, which is consistent with the results of this study.

The duration of surgery is a risk factor for delirium after hip fracture surgery in the elderly. The reasons may be that the prolonged operation duration means prolonged anesthesia time and stress duration of surgical trauma[32]. However, the function of various organs in elderly hip patients has a certain degree of degradation, and then suffers a longer surgical trauma and stress level, the body is more likely to be decompensated, and the central system of norepinephrine-acetylcholine is more likely to be unbalanced, causing brain to be extremely excited, leading to the occurrence of delirium[33, 34]. In addition, the prolonged surgery duration for elderly patients with hip fractures also means increased surgical trauma and intraoperative blood loss, excessive blood loss has aggravated the hypoxia of brain cells, resulting in the occurrence of delirium[35]. Therefore, preoperative doctors should formulate individualized surgical plans according to the specific conditions of the patients, speed up the operation process, reduce intraoperative blood loss, shorten the operation time, and reduce the use of intraoperative anesthetics.

Hypoproteinemia is one of the manifestations of patients with malnutrition, so the patient's nutritional status has a certain correlation with the occurrence of postoperative delirium[36]. Studies[37, 38] have shown that the risk of postoperative delirium among elderly patients with hip fracture is 3 times that of those with normal nutrition and 2.5 times that of those with malnutrition. Some studies[39, 40] believe that the application of high-protein nutritional supplements before surgery can improve the clinical outcome of surgical patients. Therefore, the monitor and correction of albumin level is vital to the prognosis of patients with hip fracture surgery. 
Hip fracture surgery is traumatic and usually takes a long time, thus the postoperative stress response is obvious. It disrupts the hypothalamus-pituitary-thyroid axis of the patient and affects thyroid function[41]. Thyroid hormone is an essential substance for maintaining the normal function of the central nervous system and is closely related to human mental activity[42]. Related studies[43, 44] have shown that the inflammatory response of the systemic system caused by postoperative stress can lead to delirium by increasing the permeability of the blood-brain barrier. Thyroid hormone can significantly affect the body's protein metabolism, has a diuretic effect and stimulating effect on the function of the adrenal cortex, and affects the function of the cardiovascular system, thereby affecting the blood flow of important organs such as the liver, kidney, and brain. As the number of brain cells in the elderly decreases year by year with age, the cerebral blood flow is also reduced, the metabolic level is significantly reduced, the central neurotransmitter is reduced, and the nerve conduction speed slows down, resulting in widespread brain dysfunction, coupled with the primary disease and surgical trauma, the combined effect of other influencing factors makes elderly patients become prone to postoperative delirium[45, 46$]$.

This study has certain shortcomings. First of all, the sample size of the study included in this study is small, and the possibility of false positive results cannot be ruled out. Secondly, this study is a retrospective study design, the included research indicators are limited, and future prospective studies are needed to further analyze the related factors of postoperative delirium. Finally, there is a certain difference between the incidence of delirium in this study and previous related studies. The reason may be due to the different diagnostic criteria and postoperative follow-up time for delirium, the possibility of internal bias in the study cannot be ruled out. Therefore, future studies with larger samples size are needed to further elucidate the potential influencing factors of postoperative delirium.

\section{Conclusions}

In conclusion, we have found that postoperative delirium is very common is patients with hip fracture, and for patients with age $\geq 75 \mathrm{y}, \mathrm{BMI} \geq 24 \mathrm{~kg} / \mathrm{m}^{2}$, history of delirium, estimated blood loss $\geq 400 \mathrm{ml}$, duration of surgery $\geq 120 \mathrm{~min}$, preoperative albumin $\leq 40 \mathrm{~g} / \mathrm{L}$ and $\mathrm{TSH} \leq 2 \mathrm{mU} / \mathrm{L}$, they may have higher risks for the development of postoperative delirium, early alert and preventions should be taken in advance to reduce the onset of postoperative delirium. Still, limited by sample size and study design, future studies with larger sample and rigorous design are highlighted to further ascertain the risk factors of postoperative delirium in patients with hip fracture, to provide reliable evidence to the management of hip fracture.

\section{Abbreviations}

DSM-V: Diagnostic and Statistical Manual of Mental Disorders

CAM: confusion assessment method

BMl: body mass index 
ADL: ability of daily living

T3: triiodothyronine

T4: thyroxine

TSH: thyroid stimulating hormone

FT3: free triiodothyronine

FT4: free thyroxine

$\mathrm{PaO}_{2}$ :arterial partial pressure of oxygen

$\mathrm{PaCO}_{2}$ : arterial partial pressure of carbon dioxide

\section{Declarations}

\section{Ethics approval and consent to participate}

In this study, all methods were performed in accordance with the relevant guidelines and regulations. Our study had been verified and approved by the ethical committee of Hainan Hospital of Chinese Medicine affiliated to Guangzhou University of Chinese Medicine (approval number:190084). For patients with delirium, the written informed consent from guardians for such patients were obtained. And for the patients without delirium, written informed consents were obtained from patients.

\section{Consent for publication}

Not applicable.

\section{Availability of data and materials}

All data generated or analyzed during this study are included in this published article.

\section{Competing interests}

The authors declare that they have no competing interests.

\section{Funding}

None.

\section{Author contributions}

C Y, M Y designed research; C Y, M Y, N N, L L, L P conducted research; C Y, M Y analyzed data; L P wrote the first draft of manuscript; $C Y, L$ P had primary responsibility for final content. All authors read and 
approved the final manuscript.

\section{Acknowledgments}

None.

\section{References}

1. Wolf $\mathrm{O}$, Mukka S, Ekelund J, Moller M, Hailer NP. How deadly is a fracture distal to the hip in the elderly? An observational cohort study of 11,799 femoral fractures in the Swedish Fracture Register. Acta Orthop. 2021;92(1):40-6.

2. Barrett-Lee J, Barbur S, Johns J, Pearce J, Elliot RR. Hip fractures in centenarians: a multicentre review of outcomes. Ann R Coll Surg Engl. 2021;103(1):59-63.

3. Asada M, Horii M, Ikoma K, Goto T, Okubo N, Kuriyama N, Takahashi K. Hip fractures among the elderly in Kyoto, Japan: a 10-year study. Arch Osteoporos. 2021;16(1):30.

4. Frenkel Rutenberg T, Vintenberg M, Khamudis A, Rubin T, Rutenberg R, Bdeir A, Shemesh S. Outcome of fragility hip fractures in elderly patients: Does diabetes mellitus and its severity matter? Arch Gerontol Geriatr. 2021;93:104297.

5. Meng D, Bai X, Wu H, Yao S, Ren P, Bai X, Lu C, Song Z. Patient and Perioperative Factors Influencing the Functional Outcomes and Mortality in Elderly Hip Fractures. J Invest Surg. 2021;34(3):262-9.

6. de Jong L, van Rijckevorsel V, Raats JW, Klem T, Kuijper TM, Roukema GR. Delirium after hip hemiarthroplasty for proximal femoral fractures in elderly patients: risk factors and clinical outcomes. Clin Interv Aging. 2019;14:427-35.

7. Mosk CA, Mus M, Vroemen JP, van der Ploeg T, Vos DI, Elmans LH, van der Laan L. Dementia and delirium, the outcomes in elderly hip fracture patients. Clin Interv Aging. 2017;12:421-30.

8. Yang Y, Zhao X, Dong T, Yang Z, Zhang Q, Zhang Y. Risk factors for postoperative delirium following hip fracture repair in elderly patients: a systematic review and meta-analysis. Aging Clin Exp Res. 2017;29(2):115-26.

9. Smith TO, Cooper A, Peryer G, Griffiths R, Fox C, Cross J. Factors predicting incidence of postoperative delirium in older people following hip fracture surgery: a systematic review and metaanalysis. Int J Geriatr Psychiatry. 2017;32(4):386-96.

10. Scurrah A, Shiner CT, Stevens JA, Faux SG. Regional nerve blockade for early analgesic management of elderly patients with hip fracture - a narrative review. Anaesthesia. 2018;73(6):769-83.

11. Wang $Y$, Tang J, Zhou F, Yang L, Wu J: Comprehensive geriatric care reduces acute perioperative delirium in elderly patients with hip fractures: A meta-analysis. Medicine (Baltimore) 2017, 96(26):e7361.

12. Wang CG, Qin YF, Wan X, Song LC, Li ZJ, Li H. Incidence and risk factors of postoperative delirium in the elderly patients with hip fracture. J Orthop Surg Res. 2018;13(1):186. 
13. Bai J, Liang Y, Zhang P, Liang X, He J, Wang J, Wang Y: Association between postoperative delirium and mortality in elderly patients undergoing hip fractures surgery: a meta-analysis. Osteoporos Int 2020, 31(2):317-326.

14. Marcantonio ER, Flacker JM, Wright RJ, Resnick NM. Reducing delirium after hip fracture: a randomized trial. J Am Geriatr Soc. 2001;49(5):516-22.

15. Sieber F, Neufeld KJ, Gottschalk A, Bigelow GE, Oh ES, Rosenberg PB, Mears SC, Stewart KJ, Ouanes JP, Jaberi $\mathrm{M}$, et al. Depth of sedation as an interventional target to reduce postoperative delirium: mortality and functional outcomes of the Strategy to Reduce the Incidence of Postoperative Delirium in Elderly Patients randomised clinical trial. Br J Anaesth. 2019;122(4):480-9.

16. Sachdev PS, Mohan A, Taylor L, Jeste DV. DSM-5 and Mental Disorders in Older Individuals: An Overview. Harv Rev Psychiatry. 2015;23(5):320-8.

17. Inouye SK, van Dyck CH, Alessi CA, Balkin S, Siegal AP, Horwitz RI. Clarifying confusion: the confusion assessment method. A new method for detection of delirium. Ann Intern Med. 1990;113(12):941-8.

18. Gusmao-Flores D, Salluh JI, Chalhub RA, Quarantini LC. The confusion assessment method for the intensive care unit (CAM-ICU) and intensive care delirium screening checklist (ICDSC) for the diagnosis of delirium: a systematic review and meta-analysis of clinical studies. Crit Care. 2012;16(4):R115.

19. Patel V, Champaneria R, Dretzke J, Yeung J. Effect of regional versus general anaesthesia on postoperative delirium in elderly patients undergoing surgery for hip fracture: a systematic review. BMJ Open. 2018;8(12):e020757.

20. Sieber FE, Neufeld KJ, Gottschalk A, Bigelow GE, Oh ES, Rosenberg PB, Mears SC, Stewart KJ, Ouanes JP, Jaberi M, et al. Effect of Depth of Sedation in Older Patients Undergoing Hip Fracture Repair on Postoperative Delirium: The STRIDE Randomized Clinical Trial. JAMA Surg. 2018;153(11):987-95.

21. Lee PJ, Shorten GD. Delirium after hip fracture surgery. J Clin Anesth. 2019;58:119-20.

22. Xinping $\mathrm{W}, \mathrm{Li} \mathrm{J}$, Yinghua $\mathrm{H}$. The correlation between preoperative malnutrition and delirium after hip fracture in the elderly. Practical Geriatrics. 2020;34(5):41-3.

23. Hao J, Dong B, Zhang J, Luo Z. Pre-emptive analgesia with continuous fascia iliaca compartment block reduces postoperative delirium in elderly patients with hip fracture. A randomized controlled trial. Saudi Med J. 2019;40(9):901-6.

24. Freter S, Koller K, Dunbar M, MacKnight C, Rockwood K. Translating Delirium Prevention Strategies for Elderly Adults with Hip Fracture into Routine Clinical Care: A Pragmatic Clinical Trial. J Am Geriatr Soc. 2017;65(3):567-73.

25. Guo $\mathrm{Y}$, Jia P, Zhang J, Wang $X$, Jiang $\mathrm{H}$, Jiang W. Prevalence and risk factors of postoperative delirium in elderly hip fracture patients. $J$ Int Med Res. 2016;44(2):317-27.

26. de Miguel Artal M, Roca Chacon O, Martinez-Alonso M, Serrano Godoy M, Mas Atance J, Garcia Gutierrez R. [Hip fracture in the elderly patient: Prognostic factors for mortality and functional 
recovery at one year]. Rev Esp Geriatr Gerontol. 2018;53(5):247-54.

27. Tzimas P, Samara E, Petrou A, Korompilias A, Chalkias A, Papadopoulos G. The influence of anesthetic techniques on postoperative cognitive function in elderly patients undergoing hip fracture surgery: General vs spinal anesthesia. Injury. 2018;49(12):2221-6.

28. Wennberg P, Moller M, Herlitz J, Kenne Sarenmalm E. Fascia iliaca compartment block as a preoperative analgesic in elderly patients with hip fractures - effects on cognition. BMC Geriatr. 2019;19(1):252.

29. Ernst G, Watne LO, Rostrup M, Neerland BE. Delirium in patients with hip fracture is associated with increased heart rate variability. Aging Clin Exp Res. 2020;32(11):2311-8.

30. Mak JC, Cameron ID, March LM, National H, Medical Research C. Evidence-based guidelines for the management of hip fractures in older persons: an update. Med J Aust. 2010;192(1):37-41.

31. Connolly KP, Kleinman RS, Stevenson KL, Neuman MD, Mehta SN. Delirium Reduced With Intravenous Acetaminophen in Geriatric Hip Fracture Patients. J Am Acad Orthop Surg. 2020;28(8):325-31.

32. Chen JL, Wan L, Zhu SB, Xu Y, Zheng XD. [Clinical study of Jiawei Xiaoyao Powder(JWXYP) on preventing delirium in elderly patients with hip fracture after operation]. Zhongguo Gu Shang. 2019;32(9):833-6.

33. Wu YJ, Pang QJ, Liu JT, Cao S, Hu YM. [lincidence of postoperative delirium after hip surgery in elderly patients: a meta-analysis]. Zhongguo Gu Shang. 2015;28(12):1156-61.

34. Kim JY, Yoo JH, Kim E, Kwon KB, Han BR, Cho Y, Park JH. Risk factors and clinical outcomes of delirium in osteoporotic hip fractures. J Orthop Surg (Hong Kong). 2017;25(3):2309499017739485.

35. Uzoigwe CE, O'Leary L, Nduka J, Sharma D, Melling D, Simmons D, Barton S. Factors associated with delirium and cognitive decline following hip fracture surgery. Bone Joint J. 2020;102-B(12):1675-81.

36. Harris MJ, Brovman EY, Urman RD. Clinical predictors of postoperative delirium, functional status, and mortality in geriatric patients undergoing non-elective surgery for hip fracture. J Clin Anesth. 2019;58:61-71.

37. Tao L, Xiaodong X, Qiang M, Jiao L, Xu Z. Prediction of postoperative delirium by comprehensive geriatric assessment among elderly patients with hip fracture. Ir J Med Sci. 2019;188(4):1311-5.

38. Zhang X, Tong DK, Ji F, Duan XZ, Liu PZ, Qin S, Xu KH, Di-Li XT. Predictive nomogram for postoperative delirium in elderly patients with a hip fracture. Injury. 2019;50(2):392-7.

39. Yang YP, Dong LK. Alleviation of Postoperative Delirium by Spinal Anesthesia in Elderly Patients with Hip Fracture. J Coll Physicians Surg Pak. 2019;29(8):790-1.

40. Martocchia A, Curto M, Comite F, Scaccianoce S, Girardi P, Ferracuti S, Nicoletti F, Falaschi P, Orthogeriatric G. The Prevention and Treatment of Delirium in Elderly Patients Following Hip Fracture Surgery. Recent Pat CNS Drug Discov. 2015;10(1):55-64.

41. Plaza-Carmona M, Requena-Hernandez C, Jimenez-Mola S. Predictors of Delirium in Octogenarian Patients Hospitalized for a Hip Fracture. Int J Environ Res Public Health 2020, 17(20). 
42. Ling XW, Howe TS, Koh JS, Wong MK, Ng AC. Preoperative thyroid dysfunction predicts 30-day postoperative complications in elderly patients with hip fracture. Geriatr Orthop Surg Rehabil. 2013;4(2):43-9.

43. Siru R, Alfonso H, Chubb SAP, Golledge J, Flicker L, Yeap BB. Subclinical thyroid dysfunction and circulating thyroid hormones are not associated with bone turnover markers or incident hip fracture in older men. Clin Endocrinol (Oxf). 2018;89(1):93-9.

44. Yang R, Yao L, Fang Y, Sun J, Guo T, Yang K, Tian L. The relationship between subclinical thyroid dysfunction and the risk of fracture or low bone mineral density: a systematic review and metaanalysis of cohort studies. J Bone Miner Metab. 2018;36(2):209-20.

45. Xu W, Ma H, Li W, Zhang C. The risk factors of postoperative delirium in patients with hip fracture: implication for clinical management. BMC Musculoskelet Disord. 2021;22(1):254.

46. Vakharia RM, Vakharia AM, Ameri B, Niedzielak T, Donnally CJ. 3rd, Malloy JPt: Hypothyroidism increases 90 -day postoperative complications in patients undergoing primary single level anterior cervical disectomy and fusion: a matched control analysis. J Spine Surg. 2018;4(2):274-80.

\section{Supplementary Files}

This is a list of supplementary files associated with this preprint. Click to download.

- STROBEchecklist.docx 